\title{
EL DESAPARECIDO COLEGIO SEVILLANO DE SAN BUENAVENTURA: NUEVOS DOCUMENTOS GRÁFICOS*
}

\author{
Alberto Fernández GonZÁLEZ ${ }^{1}$ \\ Universidad de Sevilla
}

\begin{abstract}
Edificado en las primeras décadas del siglo XVII, el convento-colegio de San Buenaventura era un importante conjunto arquitectónico del centro histórico de Sevilla que fue demolido, casi en su totalidad, a mediados del ochocientos, con motivo de la intervención viaria llevada a cabo en los aledaños de la actual Plaza Nueva. El artículo, que es resultado de una investigación efectuada en el Archivo General Militar de Madrid, analiza y da a conocer la planta y sección del edificio, documentos gráficos levantados en 1847 por el arquitecto académico Juan Manuel Caballero que tienen un enorme interés porque reproducen la exacta organización de su arquitectura. Para completar el estudio del colegio franciscano, se ha recuperado una descripción anónima de 1687.
\end{abstract}

Palabras clave: Convento-Colegio de San Buenaventura; Sevilla; Arquitectura barroca; Planos inéditos del siglo XIX; Juan Manuel Caballero.

\section{THE FORMER SCHOOL OF SAN BUENAVENTURA IN SEVILLE: NEW GRAPHIC DOCUMENTS}

Built in the first decades of the $17^{\text {th }}$ century, the San Buenaventura Convent-School was an important architectural ensemble in the historic centre of Seville, which was demolished, almost entirely, in the mid- $19^{\text {th }}$ century due to roadwork carried out in the area around the present Plaza Nueva. In this article, the result of research carried out in the General Military Archive of Madrid, the author analyses and divulges the floor plan and section of the building. These graphic documents, drawn by the academic architect Juan Manuel Caballero in 1847, are extremely interesting because they reproduce the exact organization of the architecture of this Franciscan school. To complete this study, an anonymous 1687 description of the building has been recovered.

Key words: San Buenaventura Convent-School; Seville; Baroque Architecture; Unpublished $19^{\text {th }}$ century plans; Juan Manuel Caballero.

Como citar este artículo / Citation: Fernández González, Alberto (2018): "El desaparecido colegio sevillano de San Buenaventura: nuevos documentos gráficos". En: Archivo Español de Arte, vol. 91, núm. 362, Madrid, pp. 127-142. https://doi.org/10.3989/aearte 2018.09.

La estructura arquitectónica y la exacta distribución del convento-colegio sevillano de San Buenaventura no se había podido esclarecer hasta ahora porque no se había encontrado ningún documento gráfico suficientemente pormenorizado, a pesar de los importantes avances llevados

* Este artículo se inscribe en la estancia de investigación realizada en varios archivos de Madrid durante los meses de julio y agosto de 2016, actividad que ha recibido una ayuda econónima del Vicerrectorado de Investigación de la Universidad de Sevilla.

${ }^{1}$ alberfer@us.es / ORCID iD: http://orcid.org/0000-0003-1582-2464 
a cabo en los últimos años, a raíz de los hallazgos de la hipótesis dibujada de su planta, fechada en 1897, y del croquis anónimo delineado en 1821 que reproduce sus dimensiones aproximadas ${ }^{2}$.

La investigación realizada en los fondos documentales conservados en el Archivo General Militar de Madrid me ha permitido localizar dos planos del edificio levantados por el arquitecto académico Juan Manuel Caballero en $1847^{3}$. El que describe las plantas baja y principal del histórico cenobio del siglo XVII (fig. 1) fue publicado en 1985 por González Cordón ${ }^{4}$, pero sin relacionarlo con autor alguno ni referirse a él en ningún momento. La escasa calidad y el reducido tamaño con que ha sido reproducido el documento gráfico, y lo sorprendente que resulta su inclusión en un libro que analiza la vivienda y la historia urbana de Sevilla en el período 18491929, temática muy alejada de la arquitectura barroca y los edificios conventuales de la ciudad, tampoco ha favorecido su difusión. Por todo ello, es perfectamente comprensible, desde luego, que en ninguno de los recientes trabajos publicados sobre San Buenaventura, a los que me referiré más adelante, se tenga en cuenta la planimetría de Caballero, llegando sus autores a aportar dibujos mucho más genéricos del conjunto arquitectónico por considerarlos relevantes. El segundo documento gráfico (fig. 2), que tampoco ha sido nunca estudiado, reproduce dos secciones del edificio: la longitudinal, que describe la estructura de la crujía este (fig. 8), situada hacia la huerta del monasterio de San Francisco; y la transversal, más valiosa todavía porque plasma el alzado originario del claustro principal (fig. 9). El trabajo de investigación se ha completado en dos archivos de Sevilla: el Histórico Municipal, donde he encontrado nuevos documentos que aportan información sobre los derribos y construcciones del ochocientos y acerca de la estructura de la actual iglesia de San Buenaventura, lo único que se conserva del conjunto del siglo XVII; y el de la Gerencia de Urbanismo, donde he localizado un expediente sobre las obras realizadas en el siglo XX. El análisis exhaustivo de los planos trazados por Juan Manuel Caballero ha constatado la solvencia de un olvidado manuscrito anónimo de 1687, texto que debe ser valorado como la fuente clave para el estudio del convento-colegio.

Para considerar adecuadamente el estado actual de las investigaciones sobre San Buenaventura habría que partir del famoso plano de Sevilla de 1771 que mandó levantar el asistente Pablo de Olavide; no obstante, por ser más significativo, prefiero reproducir el detalle correspondiente del mapa editado en Madrid en 1788 (fig. 3), un levantamiento cartográfico que su autor, Tomás López, dedicó al entonces asistente Pedro López de Lerena. La amplia e irregular manzana del céntrico sector urbano donde se insertaba el edificio está perfectamente representada. Su perímetro viario lo establecían la plaza de San Francisco, al este; las calles Catalanes, hoy Carlos Cañal, y Pajería, actual Zaragoza, al norte y sur, respectivamente; y el encuentro de estas dos vías, al oeste. En el plano también se representan, con algún detalle de interés pero de manera muy genérica, las Casas Capitulares (n. ${ }^{\circ} 161$ ), el convento de San Francisco (n. $\left.{ }^{\circ} 49\right)$ con su extensa huerta mal delimitada, el hospital de los Terceros (n. ${ }^{\circ}$ 137) y el convento de San Buenaventura (n. $\left.{ }^{\circ} 50\right)$, que comunica con la actual calle Zaragoza a través del denominado "callejón de San Buenaventura" (n. $\left.{ }^{\circ} 207\right)$.

Aunque las iniciales noticias sobre el colegio de los franciscanos hispalenses fueron aportadas por los cronistas Ortiz de Zuñiga en 1677 y Arana de Varflora en el siglo XVIII ${ }^{5}$, no cabe duda de que la primera fuente de importancia para su estudio es González de León ${ }^{6}$. El ilustre historiador sevillano visitó el edifício antes de 1844, dejándonos una acertada descripción de la iglesia, las capillas y sus respectivos tránsitos. Sus referencias a varias piezas de la clausura, como la portería, el largo corredor distributivo y el claustro principal, el único que menciona, se ajustan a las planimetrías delineadas por Caballero en 1847. A las demás estancias conventuales, eso sí, apenas se refiere, y si lo hace, como ocurre con el refectorio, la cocina y las salas contiguas, se

\footnotetext{
2 Al respecto, véanse Castillo Utrilla, 1988a: 191. Salinas Alonso, 1991: 173.

3 Plano del exconvento de San Buenaventura, 30 de enero de 1847, Archivo General Militar, Madrid (AGM), Fondos Se-10-1 y Se-10-2.

4 González Cordón, 1985: 18

5 Ortiz de Zúñiga, 1677: 202-203, 205. Arana de Varflora, 1766: 50-53.

${ }^{6}$ González de León, 1844: 193-194.
} 


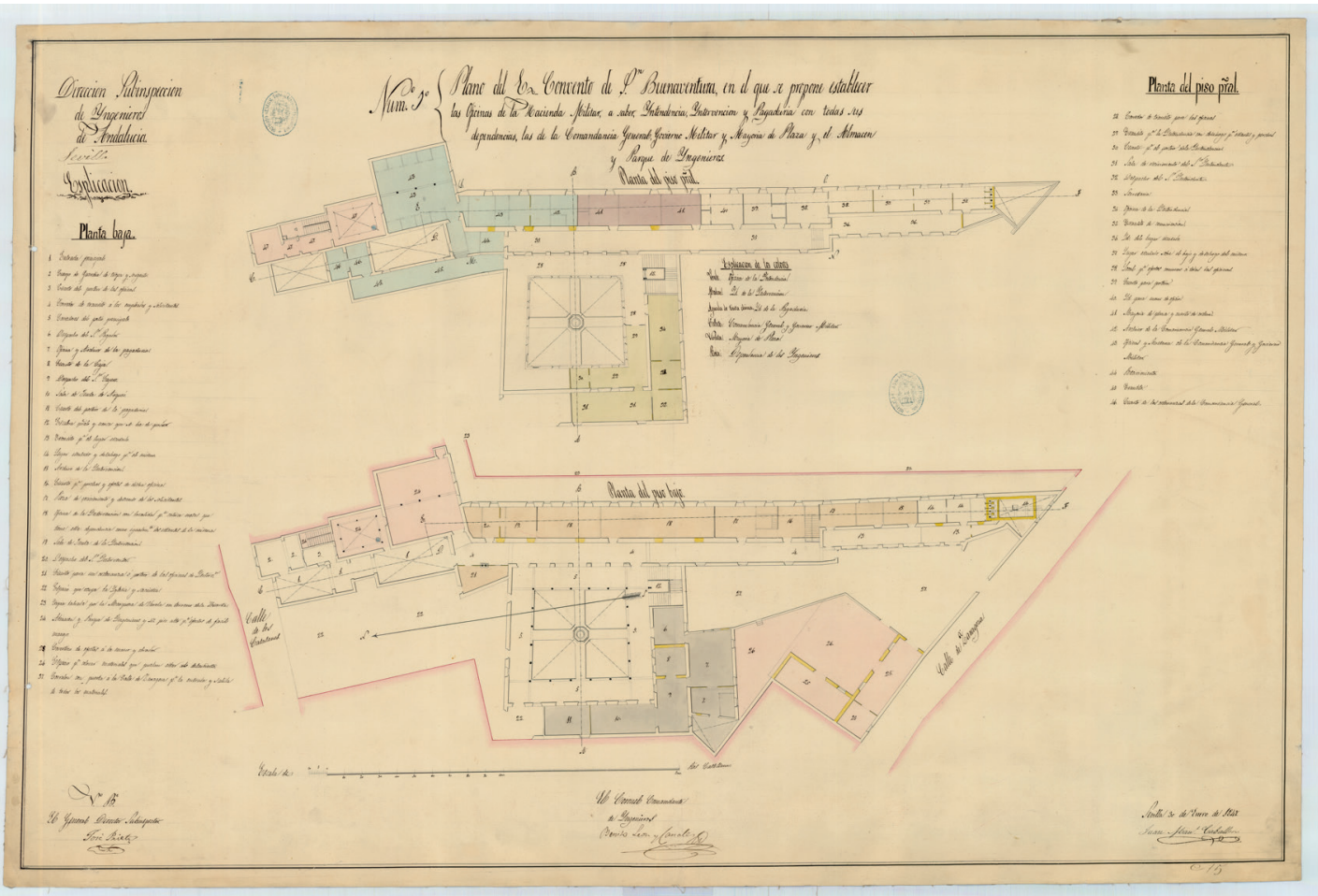

Fig. 1. Plano del convento-colegio sevillano de San Buenaventura. J. M. Caballero. 1847. Archivo General Militar de Madrid.

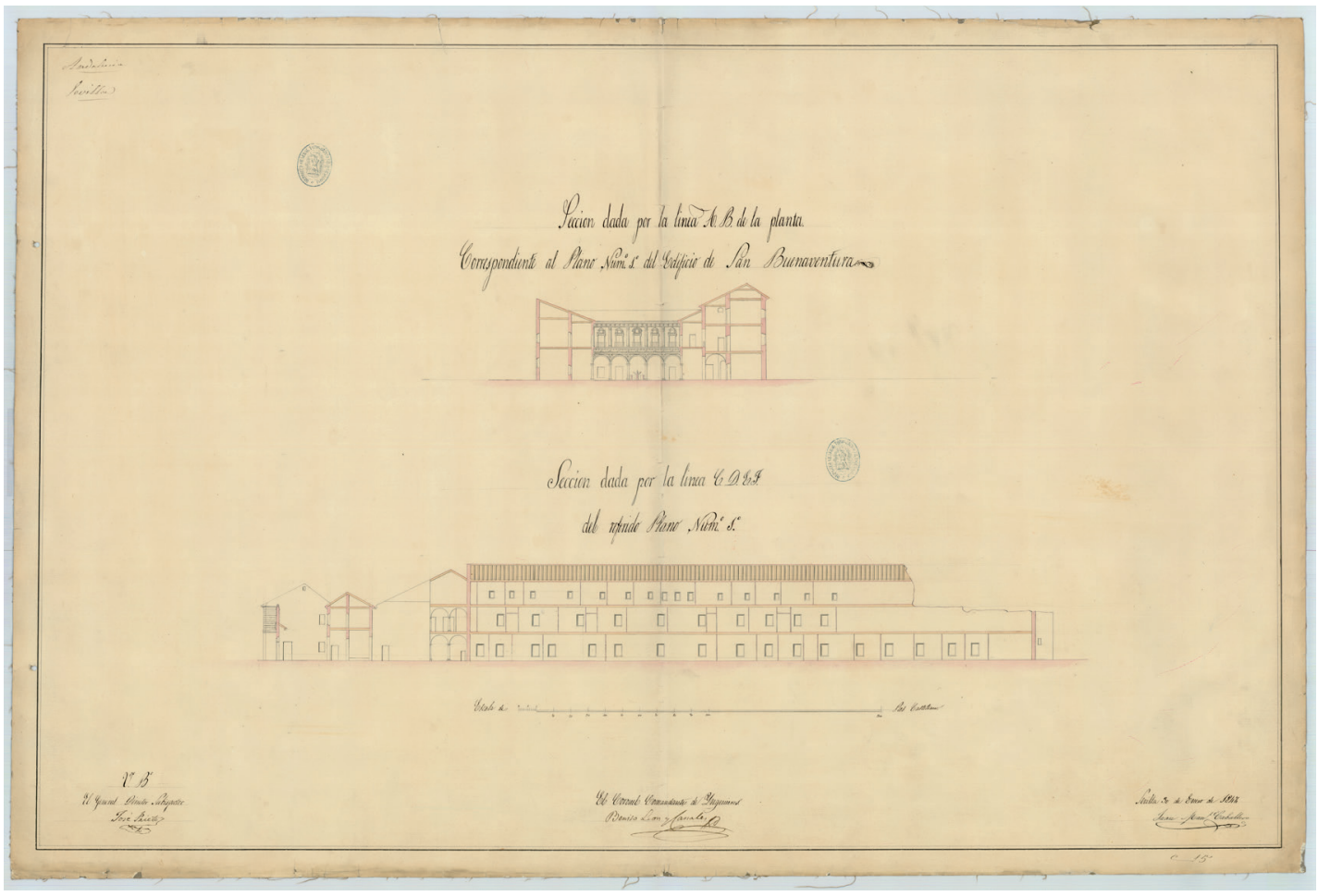

Fig. 2. Secciones longitudinales y transversales del convento-colegio sevillano de San Buenaventura. J. M. Caballero. 1847. Archivo General Militar de Madrid. 


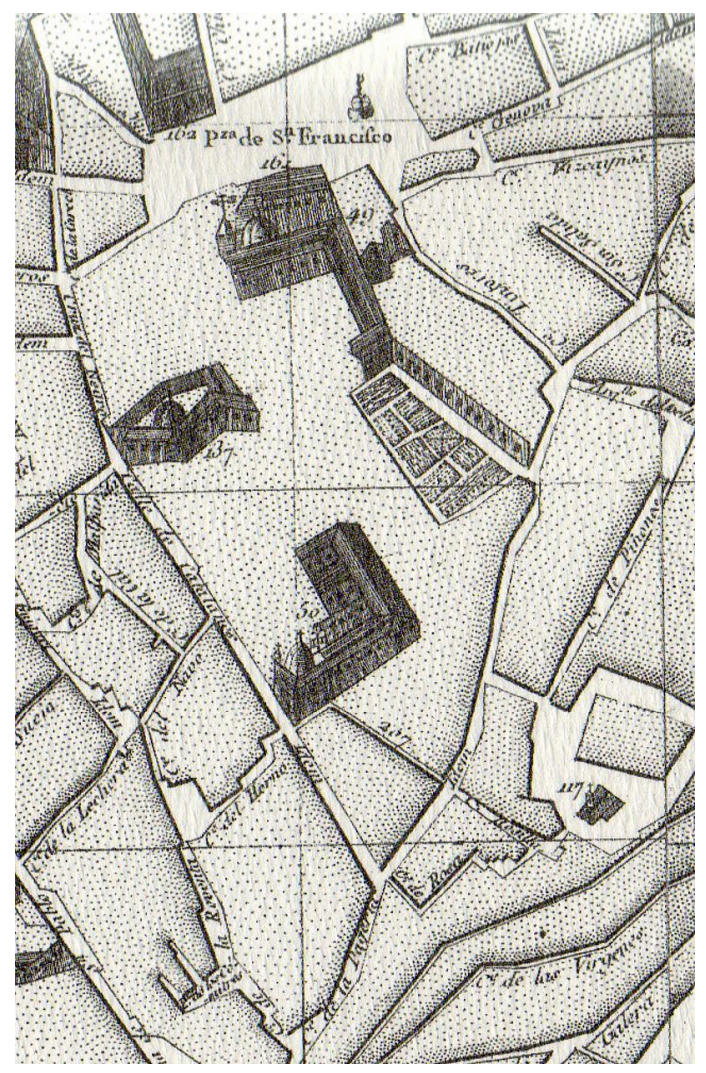

Fig. 3. Área urbana donde se asentaba el colegio. T. López. 1788. Archivo Histórico Municipal de Sevilla.

equivoca en su ubicación. Esta fuente, por tanto, es fiable, pero debe ser revisada a la luz de los nuevos documentos gráficos.

En el siglo XX, destacan las aportaciones de Ortega ${ }^{7}$, autor que en 1917 dio a conocer un manuscrito anónimo de 1687 que lleva por título Descripción del colegio e iglesia de San Buenaventura, documento injustamente olvidado que sin embargo debe ser valorado como la fuente primaria más precisa porque coincide con lo dibujado por Juan Manuel Caballero y me ha permitido identificar varias piezas del conjunto arquitectónico de ambigua adscripción. Pero también es relevante el trabajo que Castillo Utrilla ${ }^{8}$ dedicó al convento en 1988, ya que sacó a la luz la descripción y la hipótesis dibujada del edificio que elaboró fray Atanasio López de Vicuña a finales del ochocientos (fig. 4). El manuscrito de López de Vicuña es muy certero en todo lo referente a la fundación y sus históricos patrocinadores, aportando también muchos datos interesantes sobre la configuración arquitectónica de la clausura, aunque se centra especialmente en la descripción de la iglesia y sus valiosas pinturas. Es un testimono de primera mano, por supuesto, pero escrito en 1897, cuando el convento ya había sido demolido, a raíz de la intervención urbanística realizada en el entorno de la Plaza Nueva, y lo poco que permanecía en pie había sufrido varias remodelaciones. La descripción y la hipótesis dibujada de fray Atanasio López se han tenido demasiado en cuenta como fuentes de referencia y han condicionado los posteriores estudios sobre San Buenaventura. Los levantamientos arquitectónicos de Caballero, no obstante, constatan que el convento, en realidad, no disponía de tres claustros contiguos localizados hacia el sur que "formaban un magnífico frontis a la huerta" que se extendía prácticamente hasta la calle Zaragoza. Tampoco acierta López de Vicuña en la ubicación de la enfermería, el refectorio, la sala De Profundis, los dormitorios y otras piezas de la clausura.

Montoto $^{9}$, en su libro de 1973 sobre los conventos de Sevilla, trató la historia del edificio siguiendo el anónimo manuscrito de 1687 transcrito por Ortega y la descripción de González de León. Sus conclusiones sobre la arquitectura de la clausura, certeras en muchos aspectos, resultan en conjunto contradictorias, al no poder contrastar sus fuentes con documentos gráficos pormenorizados. Tres años más tarde, Martínez Ripoll ${ }^{10}$ publicó un texto sobre la iglesia de San Buenaventura, apoyándose en González de León y los documentos exhumados por López Martínez ${ }^{11}$, aunque su interés se centra en los programas iconográficos del templo ${ }^{12}$.

\footnotetext{
7 Ortega, 1917: 393-397.

8 Castillo Utrilla, 1988a: 181-187, 189.

9 Montoto, 1973: 161-164.

10 Martínez Ripoll, 1976: 9-14.

11 López Martínez, 1928a: 209-210; 1928b: 28.

12 Al respecto, véase también Martínez Ripoll, 1978: 85-92.
} 


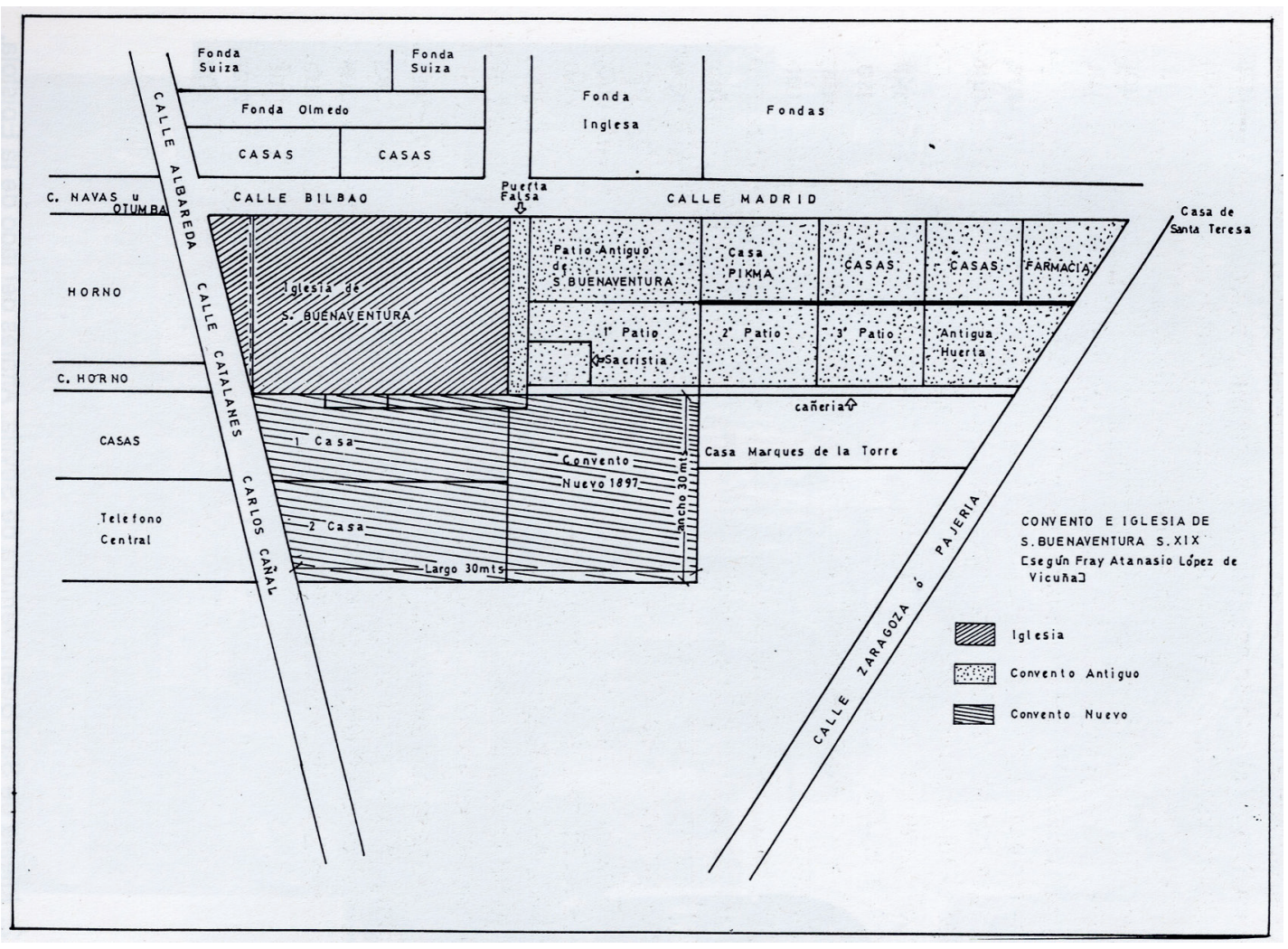

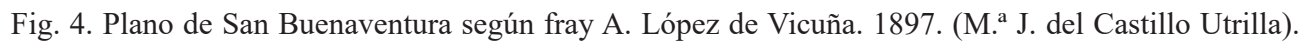

En 1991, Salinas Alonso ${ }^{13}$, tuvo el acierto de localizar en el Archivo Histórico Municipal de Sevilla un croquis anónimo de 1821 que reproduce las dimensiones aproximadas de las Casas Capitulares y los conventos de San Francisco y San Buenaventura (fig. 5). En la sección superior del documento gráfico se detalla el amplio claustro principal de San Buenaventura, sus cinco arcadas, la escalera principal, y distintos espacios de la comunidad. Esta clara aportación hacia el conocimiento arquitectónico del edificio, con todo, no es tan relevante como podría haber sido porque el desconocido autor del croquis, más que una pormenorizada descripción de la arquitectura, buscaba simplemente ubicar los edificios en la gran manzana que ocupaba el centro de la ciudad. Sobre este documento gráfico, en 2002, volvió Ollero Lobato ${ }^{14}$, relacionándolo, muy acertadamente, con las propuestas urbanísticas pergeñadas para el área del convento de San Francisco en la primera mitad del ochocientos. Su estudio del conjunto de San Buenaventura, por carencia documental, se basó sobre todo en los datos aportados por López de Vicuña. Muy recientemente, en 2009, Fernández Rojas ${ }^{15}$, en su libro sobre el patrimonio artístico de los conventos masculinos desamortizados en Sevilla, ha dedicado un capítulo a la arquitectura, escultura y pintura del convento-colegio que constituye una acertada síntesis de toda la bibliografía. Su análisis de la arquitectura, no obstante, al carecer también de nuevas fuentes documentales, reitera las descripciones de González de León y López de Vicuña.

\footnotetext{
13 Salinas Alonso, 1991: 171-174.

14 Ollero Lobato, 2002: 139-144.

15 Fernández Rojas, 2009: 157-175.
} 


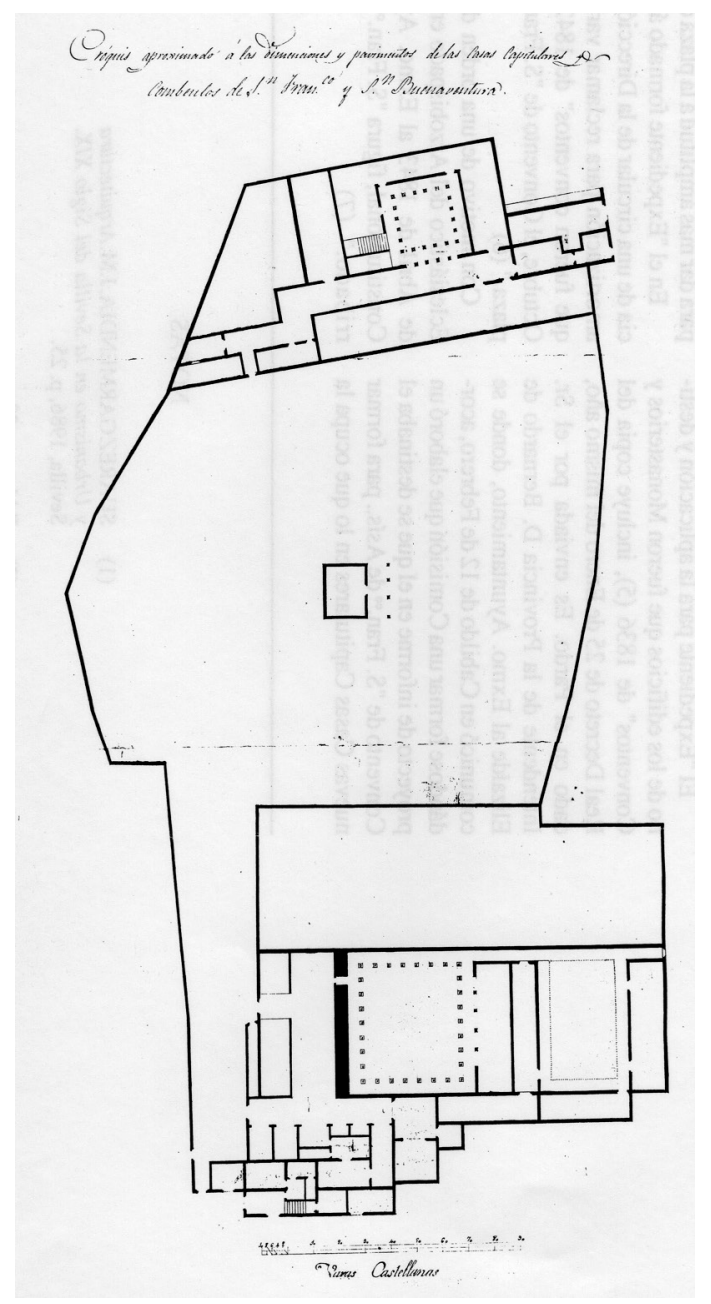

Fig. 5. Croquis de los conventos de San Francisco y San Buenaventura. Anónimo. 1821. Archivo Histórico Municipal de Sevilla.

\section{Breve síntesis histórica del convento- colegio sevillano de San Buenaventura}

Fray Luis de Rebolledo ${ }^{16}$, provincial de Sevilla, planteó la posibilidad de fundar un colegio de altos estudios teológicos con advocación a San Buenaventura en un edificio independiente del convento Casa Grande de San Francisco, donde la orden tenía su centro docente. En 1600, Isabel de Siria, viuda de Andrés Corso de Casuche, acoge la fundación bajo su patrocinio y adquiere unas casas en la antigua calle de la Mar, hoy García de Vinuesa, en las que tres años más tarde, una vez acondicionadas sus estancias, fue constituido un primer colegio. En 1605, por falta de espacio, se traslada la fundación a su emplazamiento definitivo en la collación de Santa María y se inicia la edificación, en terrenos de la huerta de la Casa Grande franciscana, del amplio conjunto arquitectónico que integra convento y colegio ${ }^{17}$. La historia constructiva de San Buenaventura no se puede establecer con precisión por falta de datos concretos, pero la comunidad, en todo caso, para garantizar el acceso principal al edificio por la calle Catalanes, tuvo que comprar algunas viviendas de particulares en esa vía, y en ellas debieron de alojarse los religiosos inicialmente. Hay constancia documental de que Diego López Bueno, en septiembre de 1622, dio las condiciones "para obras de albañilería" en el templo conventual y de que Bernardo de Velasco, futuro maestro mayor del Alcázar y la Lonja de Mercaderes, interviene en la construcción de la iglesia a partir de mayo de $1626^{18}$.

El patronato del colegio fue detentado a partir de 1626 por Tomás Mañara de Leca y Jerónima Vicentelo, padres de Miguel Mañara, el famoso gran impulsor de la Santa Caridad de Sevilla ${ }^{19}$. Tal debía de ser ya la fama y el prestigio de San Buenaventura que en el capítulo general de la orden celebrado en Toledo en 1633 fue el único centro docente elegido para toda España como estudio general, dependiendo desde ese momento de la congregación romana de

16 Sobre la biografía de este interesante personaje, véase Matute y Gaviria, 1887: 144-145.

17 Ortiz de Zúñiga, 1677: 202-203, 205. Arana de Varflora, 1789: 51. Castillo Utrilla, 1988a: 181-182.

18 En ese momento debía de estar la obra del templo muy avanzada porque las bóvedas ya constan edificadas. Al respecto, véanse López Martínez, 1928a: 209-210; 1928b: 28. Martínez Ripoll, 1976: 13-14. Arenillas, 2005: 241-243. En el manuscrito anónimo titulado Algunas obras materiales que se hicieron en este colegio y su coste, documento también dado a conocer por Ortega, 1917: 393-394, que tampoco ha sido suficientemente valorado, constan pagos anuales desde 1623 por la construcción de la "portería", la "librería" o incluso por la ejecución de la "obra del callejón de San Buenaventura", partidas económicas que parecen indicar que al tiempo que se levantaba la iglesia fueron edificadas estas piezas del convento.

19 Ortega, 1917: 392-393. 
Propaganda Fide ${ }^{20}$. El colegio formaba a los jóvenes religiosos en disciplinas relacionadas con el estudio de las Sagradas Escrituras y, singularmente, en teología escolástica positiva y moral, pero también se impartían ciclos lectivos de lógica y filosofía dirigidos a los seglares. La mayor parte del alumnado era español y portugués, aunque muchos estudiantes procedían de otros lugares de Europa, sobre todo de Irlanda y Flandes ${ }^{21}$.

Durante la ocupación napoleónica de San Buenaventura, el cenobio fue usado como cuartel por las tropas francesas, sufriendo graves daños su patrimonio artístico ${ }^{22}$. Tras la restauración fernandina, la comunidad franciscana regresó al convento realizando, entre 1813 y 1814 , obras de reconstrucción por valor de 30.000 reales $^{23}$. Durante el Trienio Liberal fueron de nuevo expulsados los religiosos del edificio, que albergó un museo de pinturas y esculturas ${ }^{24}$. Devuelto el inmueble a los franciscanos en 1824, éstos lo ocuparon hasta la exclaustración de $1835^{25}$. El segundo batallón de la milicia urbana y varias compañías de artillería se instalan en el caserón a mediados de $1837^{26}$, quedando el complejo bajo la jurisdicción castrense. El uso militar del inmueble duró unos doce años, aproximadamente ${ }^{27}$, y dio lugar al proyecto de 1847 que originó los levantamientos de Juan Manuel Caballero. El plan contemplaba la reutilización del histórico edificio como centro administrativo del ejército, pero no se llevó a cabo finalmente porque el Gobierno, en octubre de 1849, con objeto de facilitar la reordenación urbanística del entorno de la Plaza Nueva, aprueba su cesión definitiva al Ayuntamiento ${ }^{28}$.

El posterior vaciado de la gran manzana franciscana configurada entre los siglos XIII y XVII, área perfectamente integrada en la ciudad conventual hispalense ${ }^{29}$, supuso la venta y el derribo del edificio para abrir, en 1856, la calle Madrid (fig. 6). Todavía custodia el archivo municipal los diseños, firmados el 2 de marzo de 1857, que el arquitecto Manuel Galiano dio para las cinco casas construidas "en parte del solar del exconvento", tres con la fachada a la calle Madrid y dos a la de Zaragoza ${ }^{30}$. Además de la iglesia, fueron conservados el claustro principal y su gran escalera con bóveda elíptica. Estas dos últimas estructuras se integraron en los inmuebles decimonónicos, aunque Galiano, por razones estilísticas, decidió suprimir las trazas barrocas originales. Patio y escalera permanecían en pie en febrero de 1979, tal como documentan los alzados

\footnotetext{
20 Suponía un sistema de fuerte preparación teológica que asumía la ideología tridentina y que se consideraba idóneo para la formación de los franciscanos especialmente dedicados a la defensa y expansión de la fe católica en América, Filipinas y Tierra Santa. Al respecto, véanse Martínez Ripoll, 1976: 10-11. Castillo Utrilla, 1988a: 180-181.

21 Ortega, 1917: 397. Martínez Ripoll, 1976: 11.

${ }^{22}$ Una buena relación de sus tesoros artísticos, prácticamente desaparecidos en el período de ocupación, en Fernández Rojas, 2009: 162-170.

23 Castillo Utrilla, 1988a: 186.

${ }^{24}$ El Ayuntamiento liberal resuelve, en noviembre de 1822, solicitar al Gobierno la traslación de los religiosos de la Casa Grande de San Francisco al convento de San Buenaventura, con objeto de que éstos dejaran libre su edificio y poder así ampliar las Casas Consistoriales. Al respecto, véase Ollero Lobato, 2002: 149.

25 Sobre los decretos que establecían la exclaustración y desamortización general, véase Revuelta, 2010: 361-396.

26 Fue en esta fecha y no en 1836, como apunta Velázquez y Sánchez, 1872: 446-447, porque consta documentalmente que en mayo de 1837 el arquitecto Melchor Cano inspecciona el inmueble con este propósito. Informe del arquitecto Melchor Cano sobre el exconvento de San Buenaventura, 13 de mayo de 1837, Archivo Histórico Municipal, Sevilla (AHM), Col. Alfabética, Obras Públicas, caja 1427, s. fol.

27 Por las informaciones aportadas por Madoz, 1845-1850: 262, se conoce que algunas dependencias del viejo caserón estaban destinadas al Gobierno militar.

28 En el verano de 1849, con motivo de la posible instalación en el edificio del colegio real que existía en San Telmo, se abre un período de cierta inquietud municipal, pero meses más tarde, tras un suplicatorio al Gobierno, el Ayuntamiento logra su cesión definitiva. Suplicatorio del Ayuntamiento a S. M., 7 de septiembre de 1849, AHM, Col. Alfabética, Casas Consistoriales, caja 189, exp. 1.

29 Sobre el importante papel de los edificios eclesiásticos en la definición de la ciudad conventual hispalense, véase Pérez Cano, 1996: 242-252.

30 Expediente de medidas para las obras de nueva planta en el solar del exconvento de San Buenaventura, 2 de marzo de 1857, AHM, Col. Alfabética, Abecedario de Calles, exp. 1857/86, s. fol.
} 


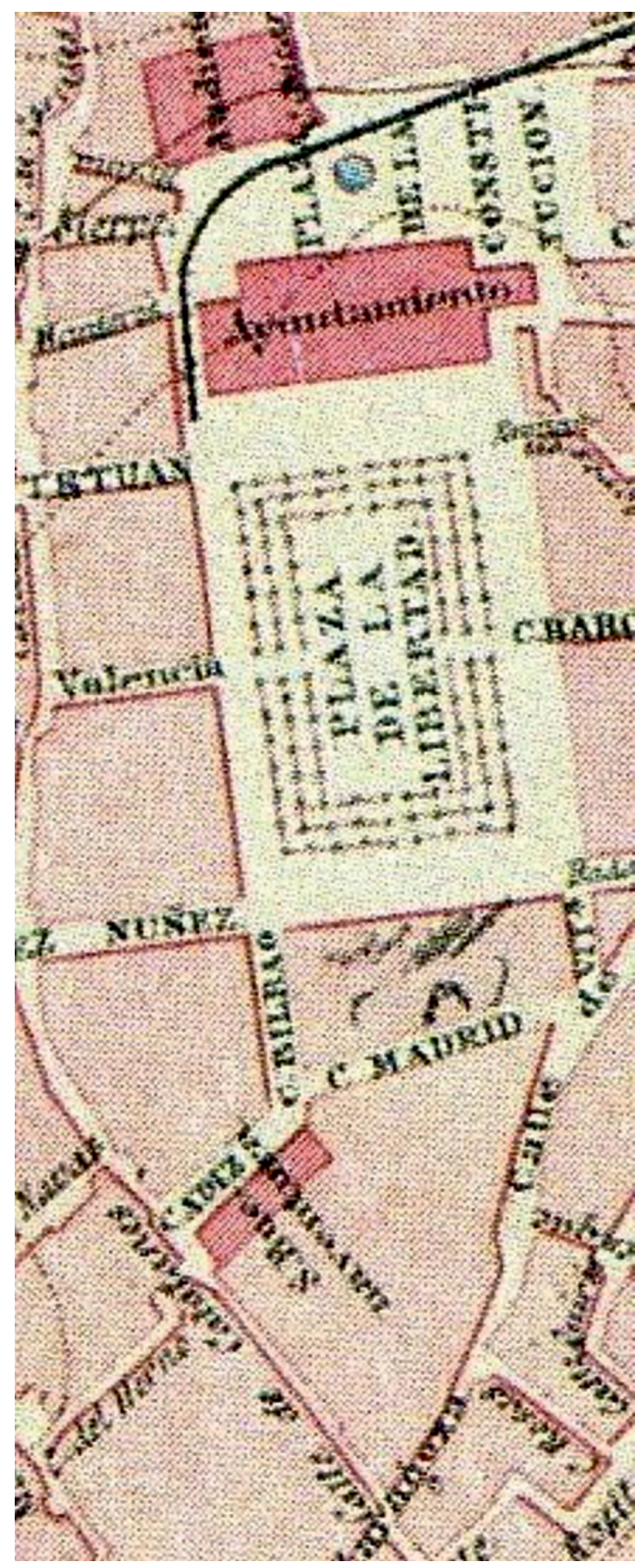

Fig. 6. Entorno de la Plaza Nueva. P. García y L. Moncada. 1870. Archivo Histórico Municipal de Sevilla. y secciones que levantó el arquitecto Fernando Mendoza Castells ${ }^{31}$. La sociedad Urbe Híspalis, en septiembre de 1992, obtuvo licencia municipal para construir el actual edificio de apartamentos, pero fue obligada por la Comisión Provincial de Patrimonio Histórico Artístico a la "restitución fiel, en sus partes esenciales", del claustro y la escalera, en concordancia con los levantamientos de Mendoza Castells ${ }^{32}$.

Para concluir, apuntar simplemente que los franciscanos volvieron a establecerse en Sevilla a finales del siglo XIX, en unas casas que adquirieron en la calle Albareda, junto al templo de San Buenaventura, donde edificaron de nueva planta un moderno convento que fue inaugurado en $1892^{33}$.

\section{El arquitecto académico Juan Manuel Caballero, autor de los levantamientos planimétricos de 1847}

Titulado por la Real Academia de Bellas Artes de San Fernando, Juan Manuel Caballero ejerció como profesor de matemáticas, desde 1835, en las Academias de Cádiz y Sevilla. En la ciudad de la Giralda, en mayo de 1841, consigue la plaza de arquitecto de los Reales Alcázares ${ }^{34}$, y tras el fallecimiento de Melchor Cano, a partir de 1844, se hizo cargo de la dirección de la sección de arquitectura de la Academia de Santa Isabel de Hungría, siendo nombrado académico de mérito el año siguiente ${ }^{35}$. Aunque no llegó a ocupar el cargo de arquitecto municipal, lo regentó varias veces en calidad de interino; y cuando Ángel de Ayala accede al puesto de arquitecto titular del Ayuntamiento, Caballero es elevado a segundo arquitecto. En Sevilla llevó a cabo varios proyectos: un plan de reforma para la Lonja del Bacalao; tres diseños de fachada para la capilla de San Onofre, en coautoría con José Gallegos Millán; y sendas propuestas de remodelación para las plazas de la Magdalena y los Descalzos, ésta última en colaboración con Ángel de Ayala ${ }^{36}$. Como perito del

31 Expediente del edificio $n^{\circ} 2$ de la calle Pedro Parias, Archivo de la Gerencia de Urbanismo, Sevilla (AGU), Licencias de obras, exp. 1595/76, s. fol.

32 Expediente del edificio $n^{\circ} 2$ de la calle Pedro Parias, AGU, Licencias de obras, exp. 1595/76, s. fol.

33 Montoto, 1973: 164.

34 Chávez González, 2004: 61-65.

35 Muro Orejón, 1961: 148.

36 González Cordón, 1985: 40. Suárez Garmendia, 1986: 98. Baena Gallé, 1999: 359-361. 
rector de la Universidad de Sevilla, interviene en la valoración realizada en 1849 del entonces colegio de San Telmo ${ }^{37}$. Desde 1855 ostentó el título de maestro mayor de primera clase de las fortificaciones y edificios militares de Cádiz ${ }^{38}$.

Los planos del convento-colegio sevillano de San Buenaventura (figs. 1 y 2) fueron levantados por Juan Manuel Caballero el 30 de enero de 1847, recibiendo la aprobación del coronel comandante de ingenieros Benito León Canales y el visto bueno de José Prieto, general director subinspector. Se trata, por tanto, de fuentes gráficas de enorme interés que reproducen el estado y la distribución que tenía el edificio pocos años antes de ser demolido. El proyecto de adaptación de las viejas estancias conventuales como dependencias militares dio lugar a los levantamientos arquitectónicos, pues el ejército, que ya ocupaba el inmueble desde mediados de $1837^{39}$, quería instalar las oficinas de la Hacienda Militar, con sus correspondientes secciones de intendencia, intervención y pagaduría; las de la Comandancia General y Gobierno Militar; y el parque de ingenieros. Aunque no he podido encontrar más datos concretos, es evidente que el plan trazado por Caballero fue un encargo privado de los militares que se realizó a espaldas del Consistorio ${ }^{40}$.

El sistema gráfico de representación utilizado por el arquitecto es similar al empleado en 1835 por León Canales, entonces ingeniero militar, para trazar las plantas y la compartimentación de varios conventos de Sevilla que se planeaban transformar en cuarteles ${ }^{41}$. Pero las planimetrías de Caballero son mucho más detalladas y están mejor ejecutadas que las levantadas por el ingeniero. Y es que Juan Manuel Caballero, al fin y al cabo, era profesor y académico de mérito y tenía que dominar, por fuerza, el sistema de representación. Para trazar las líneas arquitectónicas sobre el papel, que es el soporte empleado, usa tinta negra, y para definir los espacios de las distintas oficinas proyectadas, colores a la aguada. El verde se emplea para indicar los espacios reservados a la intendencia, el "mahón" señala las dependencias de la intervención y la aguada de tinta china las oficinas de la pagaduría. El arquitecto también utiliza el color celeste, con el que identifica todas las estancias de la Comandancia y el Gobierno Militar; el tono violeta, que señala las oficinas de la "Mayoría de plaza"; y el color rosa, que indica las dependencias de los ingenieros. Tampoco se olvidó Caballero del perímetro urbano del edificio, anotando y localizando la "Calle de los Catalanes", la "Calle de Zaragoza" y la denominada "Tapia labrada por la marquesa de Varela en terreno de la huerta", muro que entonces independizaba a San Buenaventura de la extensa huerta del convento de San Francisco.

Con objeto de facilitar la identificación de las estancias, utiliza el arquitecto un sistema alfanumérico que es explicado en un "abecedario" que ordena en tres columnas: la de la izquierda describe la planta baja del caserón; la de la derecha, el piso principal; y la central, mucho más reducida, clarifica el sentido de los colores empleados.

Las secciones longitudinal y transversal del edificio, también firmadas por Caballero y aprobadas por León y Prieto, reproducen, respectivamente, la articulación completa de la crujía este que daba a la huerta y al convento de San Francisco, y la correspondiente al claustro principal y sus piezas adyacentes hacia levante y poniente. Todos los documentos gráficos llevan escala de pies castellanos.

\section{Plantas y secciones del colegio sevillano de San Buenaventura}

La planta correspondiente al piso bajo del edificio (fig. 7) constata que el convento-colegio ocupaba todo el extremo oeste de la gran manzana del centro de Sevilla donde se insertaba, des-

${ }^{37}$ Lleó Cañal, 2004: 71.

38 Chávez González, 2004: 61

39 Véase la n. 26.

40 En este sentido, conviene recordar que el Ayuntamiento llevaba varios años detrás del edificio con la intención de incluirlo en el proyecto de la Plaza Nueva y que Caballero cesa definitivamente como técnico municipal en junio de 1846 (Suárez Garmendia, 1986: 98, 170-171).

${ }^{41}$ Sobre el ingeniero Benito León Canales, véase Fernández González, 2013: 320-321. 
de la calle Catalanes hasta la rotulada como Zaragoza. En su conjunto, la planta manifiesta una acusada forma irregular que tiene su origen en las limitaciones impuestas por el tejido urbano periférico. La heterogeneidad de las crujías, no obstante, parece indicar que los distintos espacios de la clausura se edificaron poco a poco, sin una geometría reguladora, mediante la simple adición de estructuras más o menos funcionales, probablemente subordinadas a las necesidades concretas de la comunidad franciscana. Por supuesto, las muchas vicisitudes que sufrió el edificio en el siglo XIX, que comenzaron con los destrozos producidos por las tropas napoleónicas, también podrían haber alterado sustancialmente su configuración arquitectónica. Con todo, y aunque nada tiene que ver con los arquetipos regulares en torno a un patio, no cabe duda de que el claustro principal ejerce la función de núcleo distributivo del conjunto.

Las fachadas del convento y la iglesia están alineadas con la calle Catalanes, que define el frente septentrional del edificio. Esta orientación norte se debe a la irregularidad del terreno disponible y la necesidad de adaptarse a la trama urbana. A continuación del portalón de acceso al convento ${ }^{42}$, figura delineado el zaguán descubierto ${ }^{43}$, que también aparece representado en el primer tramo de la sección longitudinal que describe la articulación de la crujía este (fig. 8). En la fachada oriental del edificio, como recoge la planta del piso bajo (fig. 7), consta dibujado, contiguo al referido zaguán, un claustro pequeño. Se distingue perfectamente su forma cuadrangular y son señaladas, además, las tres columnas que soportaban las dos arcadas que organizaban cada uno de sus cuatro frentes. Una pequeña pila circular, "de mármol de Génova"44, ocupa el ángulo suroccidental del patio. Alrededor de este claustro secundario se ubicaban el refectorio, la cocina y otras dependencias de servicio ${ }^{45}$. También se representa, contigua al corredor septentrional del claustro y con acceso directo a él, la escalera que comunicaba con la planta alta, donde se disponían "viviendas de celdas y otras oficinas" enlaza, a través de un pasaje, con una rotunda estructura cuadrada que, por su localización y dimensiones, tal vez podría ser identificada como el refectorio del colegio. Esta gran pieza ocupa la superficie equivalente a unas tres veces las dimensiones del patio, rompiendo, con su acusado volumen y disposición, la regularidad de la línea de fachada del sector nororiental del edificio, circunstancia no muy determinante porque el frente se localizaba hacia la huerta del convento de San Francisco. En su centro aparecen delineadas tres columnas dispuestas en sentido longitudinal y en eje con el muro este del claustro pequeño. La sección longitudinal (fig. 8) reproduce, en el correspondiente tramo, dos de los cuatro arcos que organizaban cada uno de sus dos pisos. Más adelante, si se sigue de nuevo la planta del piso bajo (fig. 7), consta representado el largo corredor de tránsito ${ }^{47}$ (n. $\left.{ }^{0} 4\right)$, pieza que facilita la conexión con otras dependencias importantes del edificio y que, según recoge la sección transversal (fig. 9), estaba abovedada en toda su extensión.

En la larga crujía rectangular (n. $\left.{ }^{\circ} 13-20\right)$ que abarca casi las tres cuartas partes del frente oriental (fig. 7), desde el posible refectorio hasta la calle Zaragoza, se señalan entradas y vanos hacia el corredor interior de tránsito $\left(n .^{\circ} 4\right)$. Se trata de una estructura muy regular, sin comunicación directa con el sector localizado en torno al claustro pequeño, donde también constan di-

42 En el sector izquierdo de la planta baja del edificio levantada por Caballero en 1847 (fig. 1) se lee: "1. Entrada Principal".

43 "Al convento se entra por una puerta junto a la de la iglesia, y por un zaguán descubierto se pasa a un tránsito o corredor muy largo que tiene algunas columnas y habitaciones a un lado y a otro" (González de León, 1844: 194). En la anónima descripción de 1687 se alude a "un compás de arcos sobre columnas de mármol, con puertas a la clausura y a la iglesia" (Ortega, 1917: 394). Aunque es difícil precisarlo, la sección longitudinal (fig. 8) podría reproducir algunos restos del antiguo compás de acceso. La primitiva puerta de comunicación con el templo no consta en la planta del piso bajo (fig. 7) porque en esa fecha todo el conjunto arquitectónico, salvo la iglesia, que seguía abierta al culto, se utilizaba como establecimiento militar y los dos ámbitos, por fuerza, tendrían que estar independizados.

44 En el manuscrito de 1687 consta que San Buenaventura "tiene otro segundo claustro, con su pila de agua, de pie, de mármol de Génova, y además un pozo para prevención del colegio” (Ortega, 1917: 394).

45 Ortega, 1917: 394.

46 Ortega, 1917: 395.

${ }^{47}$ En el abecedario del lado izquierdo (fig. 1) se lee: "4. Corredor de tránsito". 


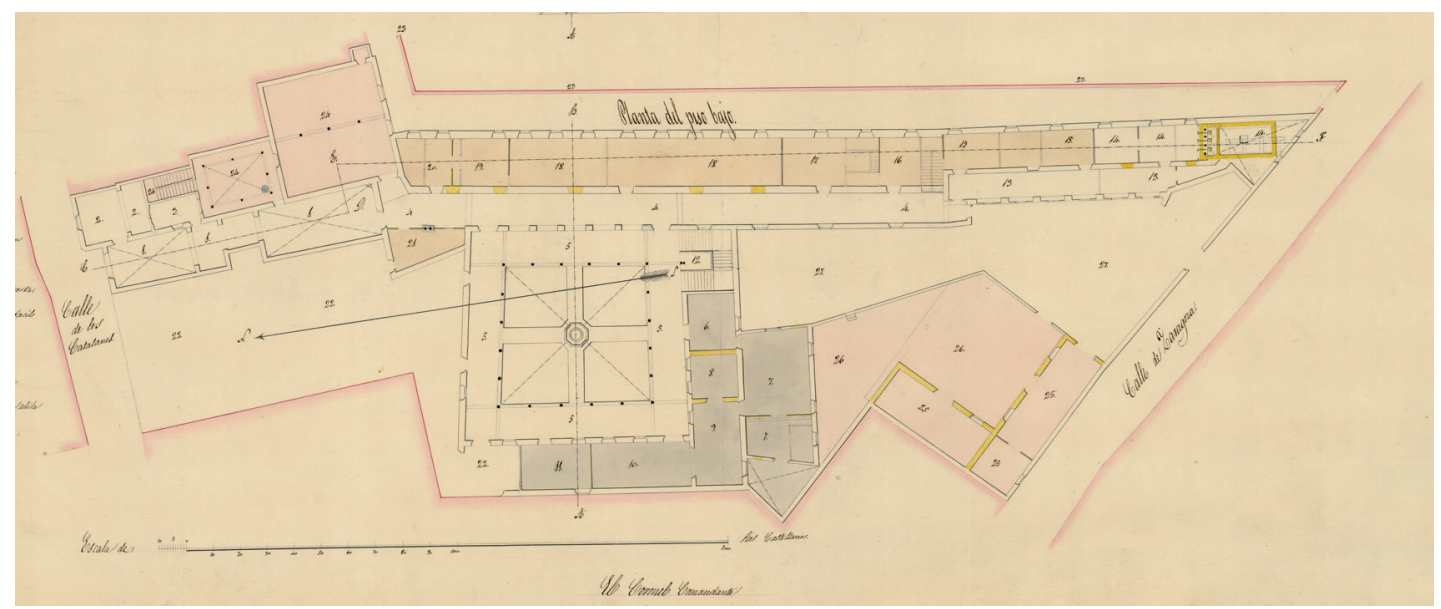

Fig. 7. Planta del piso bajo de San Buenaventura. Detalle del plano. J. M. Caballero. 1847.

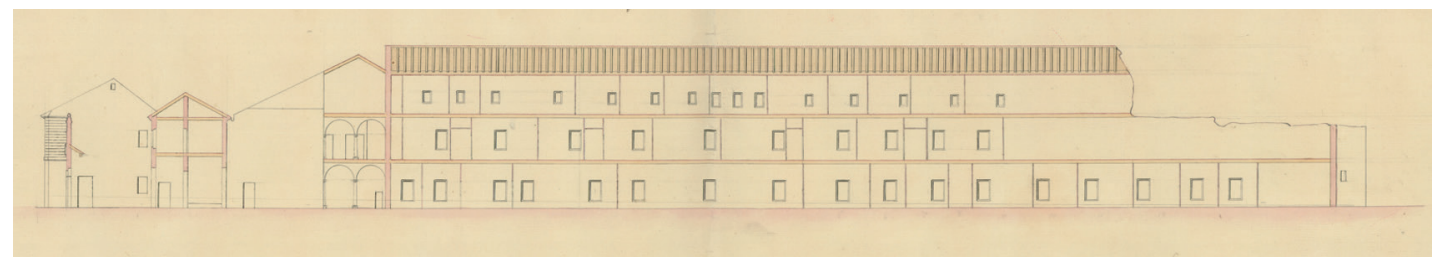

Fig. 8. Sección longitudinal de San Buenaventura. Detalle del plano. J. M. Caballero. 1847.

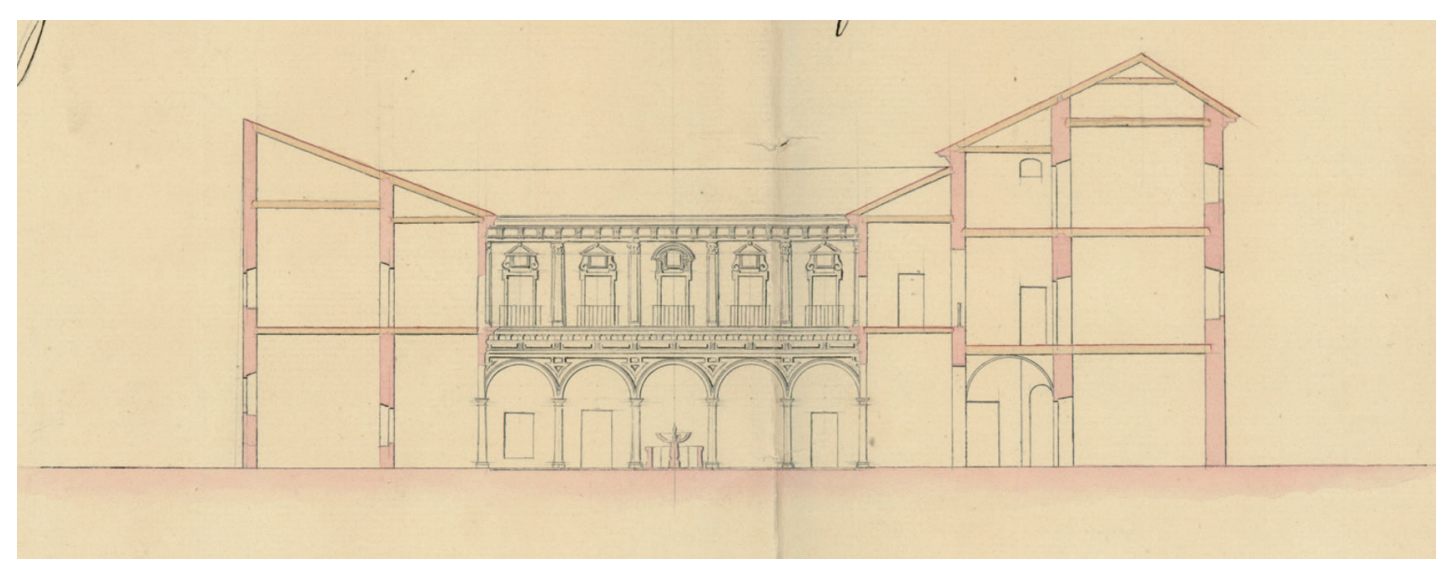

Fig. 9. Sección transversal de San Buenaventura. Detalle del plano. J. M. Caballero. 1847.

bujadas varias estancias no identificadas, una escalera de acceso al piso alto, las ventanas que se abrían en el frente este hacia la huerta y los retretes de la comunidad, que se localizan, por higiene, en el extremo meridional, aislados en un recinto cerrado que ocupa las plantas baja y alta (n. ${ }^{\circ} 14$ y 37), y a los que se llega tras recorrer sendos pasillos ${ }^{48}$ (n. ${ }^{\circ} 13$ y 36). En la sección

48 Constan en las anotaciones relativas a la planta baja (fig. 1): "13. Tránsito para el lugar excusado. 14. Lugar excusado y desahogo para el mismo"; y en las correspondientes al piso principal: "36. Tránsito del lugar excusado. 37. Lugar excusado sobre el bajo y desahogo del mismo". 
longitudinal (fig. 8), además del piso bajo y el principal, aparece delineado un ático de menores dimensiones. Las diversas salas y los muchos vanos representados en estas tres plantas me llevan a pensar que este sector del edificio podría albergar las aulas y las habitaciones de los colegiales. La sección también recoge el deterioro de la zona más meridional de la crujía, que afecta especialmente al piso principal y al ático.

Un último detalle de interés que muestra la planta del piso bajo (fig. 7) es la "tapia labrada por la marquesa de Varela en terreno de la huerta" 49 (n. $\left.{ }^{\circ} 23\right)$, es decir, el muro de separación existente entre el edificio de San Buenaventura y la huerta de la Casa Grande. La tapia se extendía desde la calle Zaragoza, que define el frente meridional del conjunto arquitectónico, hasta el probable refectorio, donde forma un ángulo acodado. Entre el muro y la fachada oriental del caserón, consta delineado un largo callejón que atraviesa la gran manzana irregular donde se asentaban los franciscanos. Se trata de un estrecho paso que facilita el tránsito entre la calle Zaragoza y el entorno de Catalanes, sin llegar a establecer, desde luego, un auténtico eje de comunicación ${ }^{50}$. En el frente sur del convento-colegio, tal como plasma el documento gráfico, existía una entrada de servicio que daba a la calle Zaragoza y comunicaba con un extenso terreno no edificado dentro del recinto ${ }^{51}\left(\mathrm{n}^{\circ}{ }^{\circ} 27\right)$.

Ocupando el centro del conjunto arquitectónico destacan las proporciones del claustro principal. Sus cuatro corredores están claramente identificados ${ }^{52}$ (n. $\left.{ }^{\circ} 5\right)$, y también las seis columnas de mármol que sustentaban cinco arcos en cada uno de sus lados. Alrededor de las galerías meridional y occidental aparecen representadas varias estancias con acceso directo al patio, salas que, según el manuscrito anónimo de 1687, albergaban "la sacristía, enfermería y cuatro celdas muy capaces" $" 53$. La ubicación de la sacristía se puede concretar más porque Caballero la sitúa justo en el ángulo suroccidental (n. $\left.{ }^{\circ} 22\right)$. La galería de levante, a través de siete arcadas, enlaza con el corredor de tránsito (n. ${ }^{\circ}$ ); y la septentrional, mediante dos puertas practicadas en el muro, comunica con la iglesia y la antesacristía ${ }^{54}$. Emplazada en el ángulo suroriental del patio, figura dibujada la escalera principal (n. $\left.{ }^{\circ} 12\right)$, la única que se proyectaba conservar ${ }^{55}$. Aunque González de Léon y López de Vicuña describen acertadamente la escalinata, aportando datos relativos a sus materiales constructivos ${ }^{56}$, la fuente más precisa es una vez más el texto de $1687^{57}$. El piso alto del edificio claustral albergaba las celdas del padre guardián y lectores, estancias que disponían de balcones orientados a la huerta del convento de San Francisco, la librería y las aulas ${ }^{58}$.

49 En esa fecha, la marquesa era la propietaria de la huerta de la Casa Grande. Se trata de "un terreno que carece de edificios de consideración, está plantada de algún arbolado nuevo y puede calificarse más bien como posesión de recreo que de producto" (Sobre la proposición del señor regidor D. Pedro García para que se lleve a cabo la obra de la gran plaza, 15 de noviembre de 1849, AHM, Col. Alfabética, Casas Consistoriales, caja 189, exp. 1, fols. 27 v.-28). La huerta será adquirida por el Ayuntamiento en 1851, con objeto de incluir el terreno en la proyectada Plaza Nueva. Copia de la escritura de venta de la huerta del lado del convento de San Francisco, 3 de enero de 1851, AHM, Col. Alfabética, Plaza de San Fernando, caja 580, s. fol.

${ }^{50}$ La función conectiva del callejón era muy necesaria por la gran extensión de la manzana. De hecho, en época de la ocupación francesa, el Gobierno local proyectó abrir una calle transversal por la huerta del convento de San Francisco a fin de comunicar las vías perimetrales de Zaragoza y Catalanes, plan que fue retomado en 1822, aunque nunca ejecutado. Sobre esta cuestión, véase Ollero Lobato, 2002: 136-137, 149-151. También Morales, 1981: 62.

51 En el abecedario de la planta baja (fig. 1) se lee: "27. Corralón con puerta a la calle de Zaragoza para la entrada y salida de todos los materiales".

52 En las anotaciones al respecto (fig. 1) consta: "5. Corredores del patio principal".

53 Ortega, 1917: 394.

${ }^{54} \mathrm{La}$ antesacristía estaba situada enfrente de la sacristía, en el pasillo angular hacia la iglesia que describe el plano de 1847 , y tenía tres puertas: "dos a la iglesia, una por donde salen las misas rezadas y otra al altar mayor, la tercera a un oratorio, alto y bajo, que está detrás del presbiterio" (Ortega, 1917: 395).

55 En el abecedario (fig. 1) se lee: "12. Escalera principal y única que se ha de quedar".

56 Al respecto, véanse González de León, 1844: 194. Castillo Utrilla, 1988a: 182-183.

57 "La escalera principal, que parte del primer claustro, se compone de tres idas, sobre seis columnas de mármol blanco, y su pasamanos de hierro en balaustres torneados; las gradas de jaspe, y en el techo una media naranja ovalada, con guarniciones de yeso y lazos de platería" (Ortega, 1917: 394).

58 Ortega, 1917: 395. Sobre la biblioteca, véase Álvarez de Toledo, 2013: 274-277. 
La sección transversal delineada por Juan Manuel Caballero (fig. 9) aporta información complementaria sobre el ático abuhardillado que en el siglo XVII acogía nueve celdas de colegiales $^{59}$, pero su representación gráfica de mayor interés, qué duda cabe, es el alzado correspondiente al frente septentrional del claustro principal, referencia documental de gran relevancia porque reproduce su configuración barroca originaria. Dibuja Caballero los sencillos placados en resalte de las enjutas de los arcos; la sintaxis decorativa de volutas, recuadros resaltados y frontones que coronaba los escenográficos balcones adintelados de la segunda planta; las pilastras de este piso alto y sus correspondientes capiteles de orden jóni$\mathrm{co}^{60}$; y la hoy también desaparecida fuente barroca $^{61}$. En este sentido, conviene recordar que el actual patio del edificio de apartamentos contiguo a la iglesia de San Buenaventura (fig. 10) es de nueva construcción y debe fecharse, como se ha explicado, a partir de septiembre de 1992. Es cierto que la empresa promotora, por exigencia de la Comisión Provincial de Patrimonio Histórico Artístico, fue obligada a reedificar el claustro antiguo siguiendo los alzados y secciones de la vieja estructura levantados en 1979 por el arquitecto Fernando Mendoza Castells ${ }^{62}$. Pero las trazas de Mendoza Castells reproducen el estado que presentaba el claustro después de la intervención de 1857 de Manuel Galiano ${ }^{63}$, es decir, el patio ochocentista, y no el barroco originario que plasma Juan Manuel Caballero en su alza-

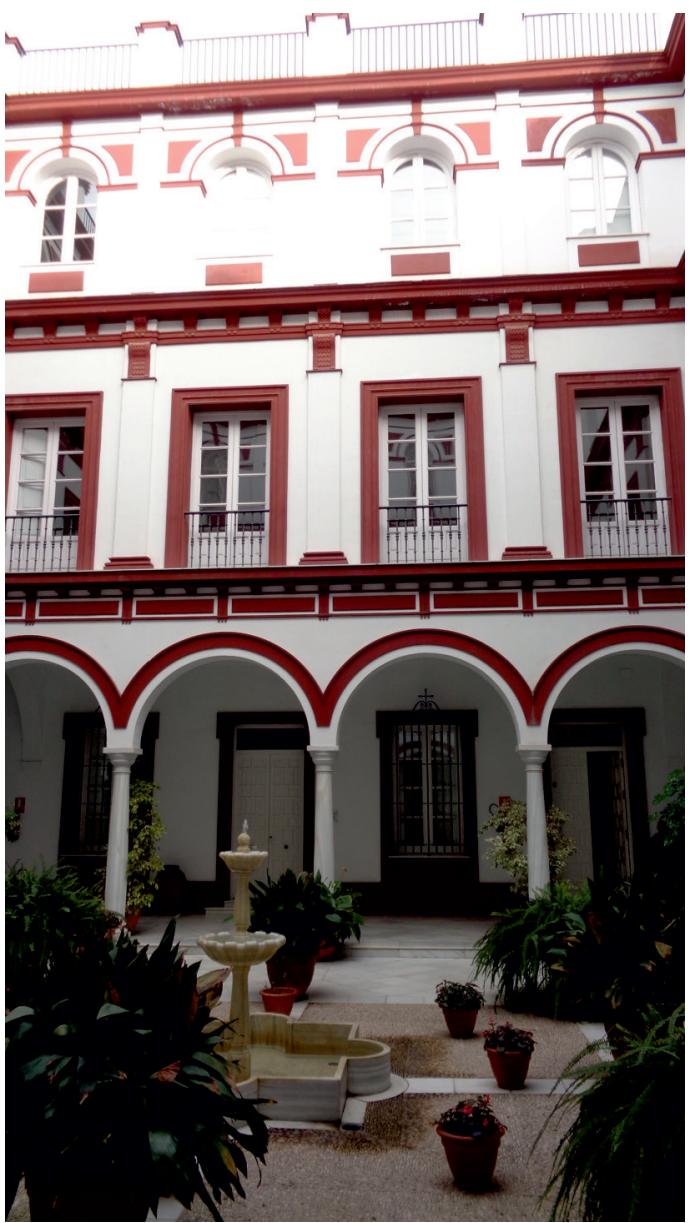

Fig. 10. Antiguo claustro principal de San Buenaventura en la actualidad. do de 1847.

Contiguas a la galería sur del claustro principal, aparecen representadas, en la planta baja (fig. 7), varias estancias (n. ${ }^{\circ} 25$ y 26) que no he podido identificar y que están circunvaladas en su flanco oriental por dos amplios espacios abiertos señalados como "corralón" (n. $\left.{ }^{\circ} 27\right)$. Es muy posible que este terreno no edificado fuera utilizado por frailes y colegiales como jardín y "patio de desahogo" ${ }^{4}$.

59 Ortega, 1917: 395.

${ }^{60}$ La referencia al orden jónico que recoge Caballero en su alzado sólo consta en el anónimo manuscrito de 1687: "[El claustro principal] ... adornado de pilastras, guarniciones y encornisamientos dóricos y jónicos" (Ortega, 1917: 394).

${ }^{61}$ Según el manuscrito de 1687 , la fuente claustral tenía una "pila de jaspe de Cabra, con taza y pedestal muy hermosos" (Ortega, 1917: 394).

${ }^{62}$ Los referidos planos de 1979 y otras informaciones complementarias figuran en su informe facultativo de 15 de junio de 1984 (Expediente del edificio n. ${ }^{\circ} 2$ de la calle Pedro Parias, AGU, Licencias de obras, exp. 1595/76, s. fol.).

${ }_{63}$ Expediente de medidas para las obras de nueva planta en el solar del exconvento de San Buenaventura, 2 de marzo de 1857, AHM, Col. Alfabética, Abecedario de Calles, exp. 1857/86, s. fol.

${ }^{64}$ En el manuscrito de 1687 consta una referencia al respecto: "Tiene en su jardín muchas plantas de hierbas y árboles frutales, y al final un patio de desahogo, muy capaz” (Ortega, 1917: 394). 


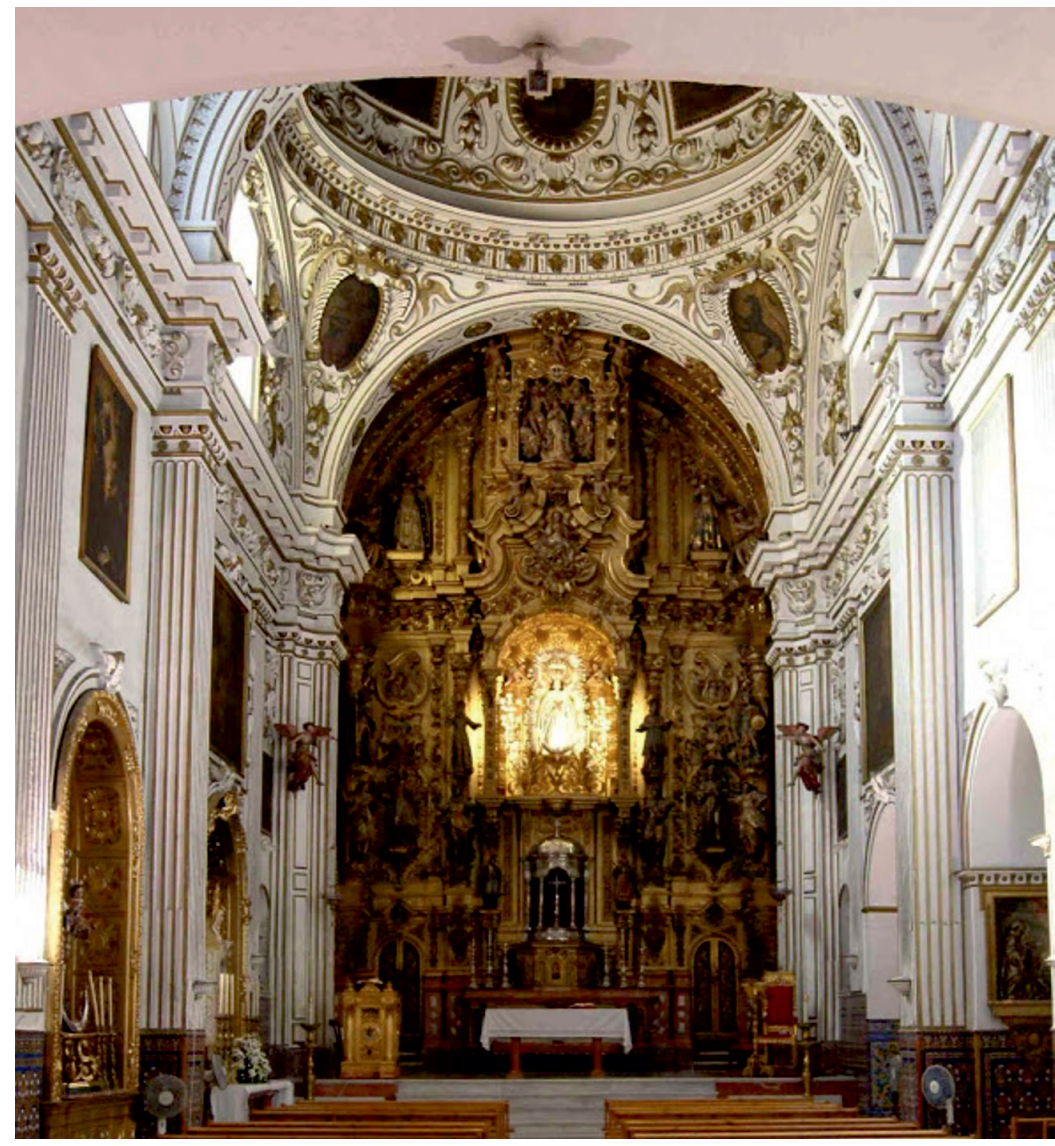

Fig. 11. Iglesia de San Buenaventura. (Fotografía: Becerra).

La planta del templo conventual de San Buenaventura no fue levantada por Caballero porque seguía abierta al culto ${ }^{65}$ y no formaba parte del proyecto previsto por el ejército. Pero el "espacio que ocupa la iglesia y sacristía" está perfectamente delimitado en el plano e identificado con el n. ${ }^{\circ} 22$. La sacristía, cuadrangular y "de diez varas de largo y seis de ancho"66, ocupaba el sector noroccidental del claustro principal, tal como recoge el arquitecto en su planimetría del convento. La iglesia actual (fig. 11), de planta rectangular con crucero muy poco marcado, coro a los pies, bóveda de cañón con lunetos y cúpula sobre pechinas, consta de nave central y otra de tránsito colateral en el lado de la epístola que fue edificada en época moderna ${ }^{67}$. Se ha apuntado que las actuales dos naves estructurales son producto de la demolición de la nave del evangelio en 1863 y las reformas llevadas a cabo a finales del siglo XIX y primeras décadas del XX en el frente oeste y que el templo, antes de estas intervenciones, tenía una planta rectangular de tres naves, que era la original del siglo XVII ${ }^{68}$. Es extraño, con todo, que González de León, que visitó la iglesia los primeros años de la década de 1840, antes, por tanto, de la demolición de la supuesta nave del evangelio, la describa "de sólo una nave con su capilla mayor" y a continuación centre su atención en las capillas colaterales ${ }^{69}$. López de Vicuña explica el edificio en términos

\footnotetext{
65 Madoz, 1845-1850: 262.

66 Según el manuscrito anónimo de 1687, la sacristía era "una muy buena quadra, de diez varas de largo y seis de ancho; tiene sus repartimientos de oficinas y aguamanil, muy capaces" (Ortega, 1917: 395).

${ }^{67}$ El estudio arquitectónico del templo en Fernández Rojas, 2009: 160-162.

${ }_{68}$ Castillo Utrilla, 1988a: 189. Fernández Rojas, 2009: 161.

${ }^{69}$ González de León, 1844: 193-194.
} 
similares: "el templo de San Buenaventura forma una sola y espaciosa nave"70. Y el anónimo autor del manuscrito de 1687, la fuente más antigua y fiable, describe las capillas y el estilo y ornamentación de la iglesia, pero no menciona las tres naves estructurales propuestas ${ }^{71}$.

En el Archivo Histórico Municipal de Sevilla he localizado un croquis levantado por el arquitecto Balbino Marrón en julio de 1856 que plasma el frente oeste de la iglesia de San Buenaventura antes de ser remodelado ${ }^{72}$ (fig. 12). El documento gráfico fue delineado con motivo de un convenio entre el Ayuntamiento y la empresa constructora de la Plaza Nueva que establecía la cesión municipal del "trozo de callejuela tapiada lindante con la iglesia de San Buenaventura hasta llegar a la sacristía, adonde se trasladarán las capillas que existen en la parte opuesta del templo, y puedan derribarse estas para dar a la calle de Cádiz la anchura conveniente" 73 . El croquis de Marrón es un simple esbozo del que no es posible sacar conclusiones definitivas, pero detalla el muro oeste del templo y su aproximada disposición respecto a la antesacristía y sacristía. Teniendo en cuenta que la actual nave de tránsito colateral por ese lado se ha edificado, por tanto, en el terreno antes ocupado por el callejón, pienso que es muy posible que la iglesia barroca,

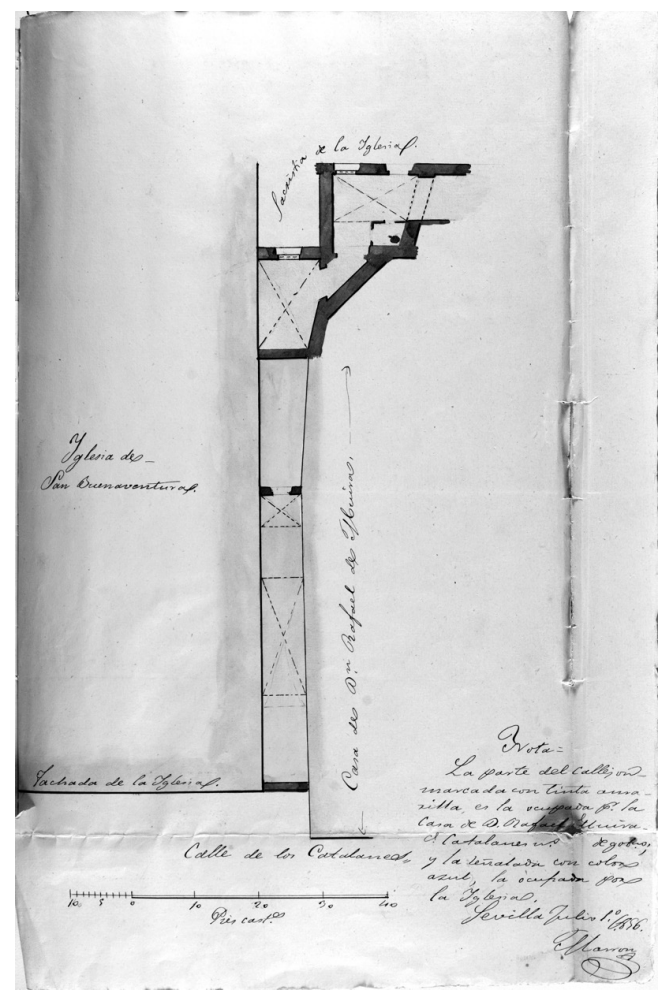

Fig. 12. Croquis. B. Marrón. 1856. Archivo Histórico Municipal de Sevilla. como tantas otras de la orden franciscana, respondiera originalmente al tipo de planta rectangular de una sola nave de grandes dimensiones con capillas laterales. En Sevilla, este esquema constructivo se constata en la iglesia conventual franciscana de Nuestra Señora de la Consolación y, tal vez, en la de la desaparecida Casa Grande de San Francisco ${ }^{74}$.

\section{Conclusiones}

En la ciudad conventual hispalense de la Edad Moderna, el convento-colegio de San Buenaventura ocupaba el flanco oeste de una gran manzana franciscana que estaba conformada en su interior por un extenso vacío de tierras de cultivo. Con la desamortización y el posterior proceso especulativo ligado a la explotación del suelo urbano, el gran solar eclesiástico, opaco a las necesidades de la ciudad decimonónica, se transforma en una plaza cívica y funcional que ordena y moderniza un importante sector del centro histórico de Sevilla.

70 Castillo Utrilla, 1988a: 184.

${ }^{71} \mathrm{Al}$ tratar sobre la estructura del templo, sólo explica que "se compone su cuerpo principal de treinta varas de largo, desde la puerta de la calle al testero del presbiterio, y diez de ancho" (Ortega, 1917: 395-397).

72 Croquis con el terreno ocupado por la iglesia de San Buenaventura y la casa de Rafael de Mihura y calle Catalanes, 1 de julio de 1856, AHM, Col. Alfabética, Obras Públicas, caja 172, exp. 89.

${ }^{73}$ Convenio promovido entre el Ayuntamiento y la empresa de la nueva plaza, 5 de agosto de 1856, AHM, Col. Alfabética, Obras Públicas, caja 172, exp. 89. Es decir, lo que se derriba, en realidad, son las capillas, no la supuesta nave del lado del evangelio.

${ }^{74}$ Castillo Utrilla, 1988b: 55, 129. 
El análisis pormenorizado de las plantas y secciones levantadas por Juan Manuel Caballero ha permitido dar un paso más en el conocimiento de las principales estancias, que se han podido identificar y localizar, en la definición de la compartimentación interior y en los usos privados del conjunto arquitectónico. Además del relevante papel de eje distribuidor que tenía el claustro principal, del que se ha podido precisar su configuración barroca originaria, se ha constatado la funcionalidad de la monumental crujía oriental y la existencia de un núcleo autónomo de servicio en torno al patio pequeño. En definitiva, los testimonios gráficos de 1847 han rescatado del olvido un patrimonio arquitectónico significativo de la ciudad de Sevilla, hoy desaparecido.

\section{BIBLIOGRAFÍA}

Álvarez de Toledo, Amparo (2013): “Colegio de San Buenaventura”. En: Peñalver Gómez, Eduardo (coord.): Fondos y procedencias. Bibliotecas en la Biblioteca de la Universidad de Sevilla, Sevilla: Universidad, pp. 274-277.

Arana de Varflora, Fermín (1766): Compendio descriptivo de la muy noble y muy leal ciudad de Sevilla metrópoli de Andalucía. Sevilla: Manuel Nicolás Vázquez.

Arenillas, Juan Antonio (2005): Del Clasicismo al Barroco. Arquitectura sevillana del siglo XVII. Sevilla: Diputación.

Castillo Utrilla, María José del (1988a): "La iglesia y el colegio de San Buenaventura de Sevilla en el siglo XIX". En: Laboratorio de Arte, 1, Sevilla, pp. 179-197.

Castillo Utrilla, María José del (1988b): El convento de San Francisco, Casa Grande de Sevilla. Sevilla: Diputación.

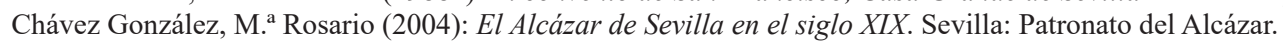

Baena Gallé, José Manuel (1999): "Un conflicto urbanístico en la Sevilla del siglo XIX: los proyectos de fachada para la capilla de San Onofre". En: Laboratorio de Arte, 12, Sevilla, pp. 355-366.

Fernández González, Alberto (2013): "El desaparecido monasterio sevillano de San Agustín: planos inéditos del siglo XIX". En: Archivo Español de Arte, LXXXVI, 344, Madrid, pp. 311-330.

Fernández Rojas, Matilde (2009): Patrimonio artístico de los conventos masculinos desamortizados en Sevilla durante el siglo XIX: Trinitarios, Franciscanos, Mercedarios, Jerónimos, Cartujos, Mínimos, Obregones, Menores y Filipenses. Sevilla: Diputación.

González Cordón, Antonio (1985): Vivienda y Ciudad. Sevilla 1849-1929. Sevilla: Ayuntamiento.

González de León, Félix (1844): Noticia artística de todos los edificios públicos de esta muy noble ciudad de Sevilla. Sevilla: José Hidalgo.

Lleó Cañal, Vicente (2004): "El palacio de San Telmo en el siglo XIX”. En: PH. Boletín del Instituto Andaluz de Patrimonio Histórico, 51, Sevilla, pp. 71-76.

López Martínez, Celestino (1928a): Arquitectos, escultores y pintores vecinos de Sevilla. Sevilla: Rodríguez Giménez.

López Martínez, Celestino (1928b): Retablos y esculturas de traza sevillana. Sevilla: Rodríguez Giménez.

Madoz, Pascual (1845-1850): Diccionario Geográfico Estadístico Histórico de Andalucía. Sevilla. Valladolid, facs. de la ed. de Madrid: Ámbito.

Martínez Ripoll, Antonio (1976): La iglesia del Colegio de San Buenaventura. Estilo e iconografía. Sevilla: Diputación.

Martínez Ripoll, Antonio (1978): Francisco de Herrera “el Viejo”. Sevilla: Diputación.

Matute y Gaviria, Justino (1887): Hijos de Sevilla señalados en santidad, letras, armas, artes o dignidad, vol. II. Sevilla: Archivo Hispalense.

Montoto, Santiago (1973): Esquinas y conventos de Sevilla. Sevilla: Universidad.

Morales, Alfredo (1981): El Ayuntamiento de Sevilla. Arquitectura y simbología. Sevilla: Ayuntamiento.

Muro Orejón, Antonio (1961): Apuntes para la historia de la Academia de Bellas Artes de Sevilla. Sevilla: Imprenta provincial.

Ollero Lobato, Francisco (2002): "Propuestas urbanísticas para el área del convento de San Francisco de Sevilla durante la primera mitad del siglo XIX". En: Archivo Hispalense, 258, Sevilla, pp. 135-151.

Ortega, Ángel (1917): Las casas de estudios en la provincia de Andalucía. Madrid: Imprenta G. López del Horno.

Ortiz de Zúñiga, Diego (1677): Anales eclesiásticos y seculares de la muy noble y muy leal ciudad de Sevilla, metrópoli de la Andalucía, vol. IV. Madrid: Imprenta Real.

Pérez Cano, María Teresa (1996): Patrimonio y Ciudad. El sistema de los conventos de clausura en el centro histórico de Sevilla. Sevilla: Universidad.

Revuelta, Manuel (2010): La Exclaustración (1833-1840). Madrid: CEU Ediciones.

Salinas Alonso, Víctor (1991): "Dos planos del convento y huerta de San Francisco en Sevilla". En: Atrio, 3, Sevilla, pp. 171-174.

Suárez Garmendia, José Manuel (1986): Arquitectura y urbanismo en la Sevilla del siglo XIX. Sevilla: Diputación.

Velázquez y Sánchez, José (1872): Anales de Sevilla de 1800 a 1850. Sevilla: Hijos de Fé.

Fecha de recepción: 12-I-2017

Fecha de aceptación: 25-IV-2017 